\title{
Article \\ Individual Adjustment of Contraction Parameters for Effective Swing Assist Using a Pneumatic Artificial Muscle in the Elderly
}

\author{
Haruki Toda $^{1, *(D)}$, Tsubasa Maruyama ${ }^{1}$, Yuichi Kurita ${ }^{2,3}{ }^{\mathbb{D}}$ and Mitsunori Tada ${ }^{1}(\mathbb{D})$ \\ 1 Digital Human Research Team, Artificial Intelligence Research Center, National Institute of Advanced \\ Industrial Science and Technology, 2-3-26, Aomi, Koto, Tokyo 135-0064, Japan; \\ tbs-maruyama@aist.go.jp (T.M.); m.tada@aist.go.jp (M.T.) \\ 2 Graduate School of Advanced Science and Engineering, Hiroshima University, 1-4-1, Kagamiyama, \\ Higashi-Hiroshima City, Hiroshima 739-8527, Japan; ykurita@hiroshima-u.ac.jp \\ 3 JST, PREST, 4-1-8 Honcho, Kawaguchi, Saitama 332-0012, Japan \\ * Correspondence: haruki-toda@aist.go.jp; Tel.: +81-(33)-5998201; Fax: +81-(35)-5005233
}

Citation: Toda, H.; Maruyama, T.;

Kurita, Y.; Tada, M. Individual

Adjustment of Contraction

Parameters for Effective Swing Assist Using a Pneumatic Artificial Muscle in the Elderly. Appl. Sci. 2021, 11, 4308. https://doi.org/10.3390/ app11094308

Academic Editor: Filomena Soares

Received: 17 March 2021

Accepted: 5 May 2021

Published: 10 May 2021

Publisher's Note: MDPI stays neutral with regard to jurisdictional claims in published maps and institutional affiliations.

Copyright: () 2021 by the authors. Licensee MDPI, Basel, Switzerland. This article is an open access article distributed under the terms and conditions of the Creative Commons Attribution (CC BY) license (https:// creativecommons.org/licenses/by/ $4.0 /)$.
Featured Application: Our pneumatic artificial muscle driver is expected to reduce the risk of stumbling during walking in the elderly.

\begin{abstract}
Leg swing during walking is controlled by hip and knee flexion motions. This study examined the effect of swing assist using a pneumatic artificial muscle (PAM) driver system on hip and knee motions and gait performance in the elderly. The participants consisted of 10 healthy elderly individuals. Two PAMs were attached to each participant's left hip joint, and a pressure sensor was inserted under the right heel as the trigger. PAM contraction parameters could be controlled through a smartphone, i.e., the delay from trigger to contraction and the contraction duration. These parameters were randomly changed to 0,100 , or $200 \mathrm{~ms}$ for the delay and 100, 200, or $300 \mathrm{~ms}$ for the contraction. Four combination patterns of delay and contraction duration were observed as the parameter settings for maximizing the hip flexion angle. During walking with the PAM assistance, the hip and knee flexion angles in the swing phase and hip angular excursion of the elderly were significantly increased without altering the gait performance. The findings show that our PAM driver system can realize effective swing assist through changing temporal parameter settings for the PAM contraction in the elderly.
\end{abstract}

Keywords: pneumatic artificial muscle; driver system; elderly; smartphone; swing assistance; joint angle; gait

\section{Introduction}

Japan has become a super-aging society, where people aged over 65 years old account for $28.4 \%$ of the population [1]. Falls and fractures during walking decrease the ability to walk [1]; therefore, they should be prevented in older people. A risk factor for falls in the elderly is stumbling during walking [2]. Stumbling occurs because of the large variability and low height of foot clearance during the swing phase [3-5]. Foot clearance is mainly controlled by hip and knee flexion movements [6]. Older adults have significantly smaller knee flexion angles than younger adults [7]. Furthermore, stroke patients have small hip and knee flexion angles [8]. Thus, there is a need to increase the hip and knee flexion angles during the swing phase to decrease the risk of stumbling.

Recently, robotic gait rehabilitation has been shown to be useful in people with paralysis and muscle weakness $[9,10]$. Robotic devices can realize powerful assistance of joint motions through the generation of a large torque. This type of rehabilitation has achieved significant improvements in speed [9], joint angles [11], and muscle activity [12] during walking. However, these devices have disadvantages, such as difficulty in wearing, 
high cost, large weight, and limited availability. In addition, a physical therapist must be nearby to assist with the wearing and operation of the robotic devices.

Wearable assistive devices have also been developed for gait rehabilitation. The pneumatic artificial muscle (PAM) is a useful actuator for such devices [13]. Although the PAM cannot generate a large assistive torque, it has certain benefits, such as low cost, small weight, and flexibility [14]. Thus, the PAM can support lower limb joint motions during walking [13,15-18].

In previous studies [13,17], constant contraction parameters have been employed for individuals in assisting with the hip flexion motion during the swing phase. However, the temporal parameters for maximizing the hip flexion angle may differ among individuals. Consequently, we have developed a PAM driver system that can change the delay of contraction from the trigger, as well as the contraction duration, through a smartphone $[19,20]$. By realizing the control of the PAM through a smartphone, the users can wear the PAM by themselves, and the therapist can tune the parameters from a distance. Using this system, the hip and knee flexion angles of healthy young adults in their 20s can be significantly increased compared to the angles without the PAM assistance with individual differences in the parameter settings [14].

However, no study has reported the effectiveness of swing assist using a PAM driver system for the hip and knee joint motions of the elderly. Elderly people have a low walking ability and different temporal and kinematic characteristics of gait, compared with those of young people $[7,21,22]$. In addition, the elderly experience functional decline with aging and low balance capacity [23]. Consequently, it is unclear whether the parameter settings for maximizing the hip flexion angle are the same for the elderly those of the young population; the elderly may differ from younger people in their responsiveness to the PAM assistance. To clarify the effectiveness of swing assist using our PAM driver system and the characteristics of its effect for the elderly, it is necessary to evaluate its assisting effect in the elderly.

This study examined the parameter settings for maximizing the hip flexion angle in elderly subjects. Additionally, it evaluated the effect of swing assist using a PAM driver system on the hip and knee joint angles during the swing phase and gait performance.

\section{Materials and Methods}

\subsection{Participants}

In total, 10 healthy elderly adults (age: $65.3 \pm 2.7$ years old, five males and five females; height: $1.62 \pm 0.06 \mathrm{~m}$; weight: $58.3 \pm 11.5 \mathrm{~kg}$; BMI: $22.0 \pm 3.0 \mathrm{~kg} / \mathrm{m}^{2}$ ) participated in this study. All participants were able to walk independently without any assistive devices (such as canes, crutches, or orthopedic devices). The exclusion criteria included neurological disorders, trauma, and orthopedic issues.

\subsection{Experimental Setup}

Figures 1 and 2 show the experimental setup used in this study. An inertial measurement unit (IMU)-based motion capture (MoCap) system was used to measure the joint angle of the lower limbs during walking. Prior to data collection, an individual digital human model was constructed using DhaibaWorks-our self-developed software [24]. The dimensions of the model were estimated from the participant's height and weight according to the Japanese body dimensions database [24]. Eight IMUs (MTw; Xsens, Enschede, the Netherlands) were attached to the sternum, sacrum, thighs, shanks, and feet corresponding to the segments of the digital human model. All the participants wore the same shoes (BioTF 02; Moonstar, Fukuoka, Japan) during the experiment. 


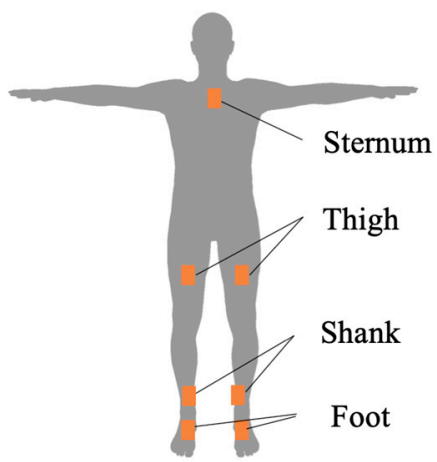

Front side

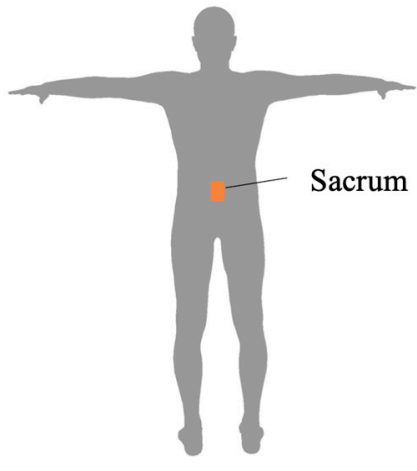

Back side

Figure 1. Placement of the inertial measurement units.

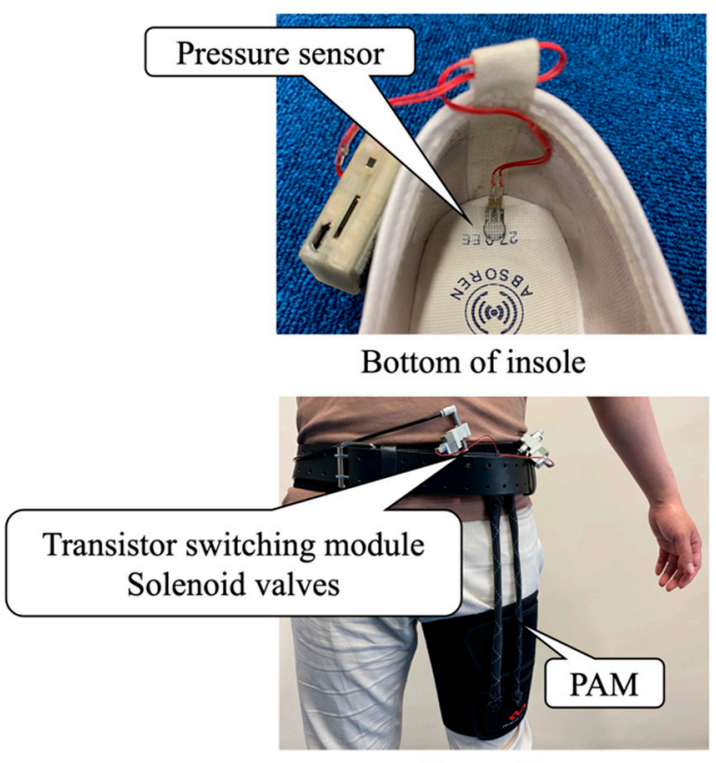

Front side

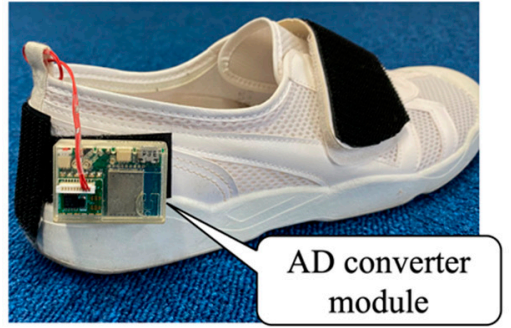

Shoes

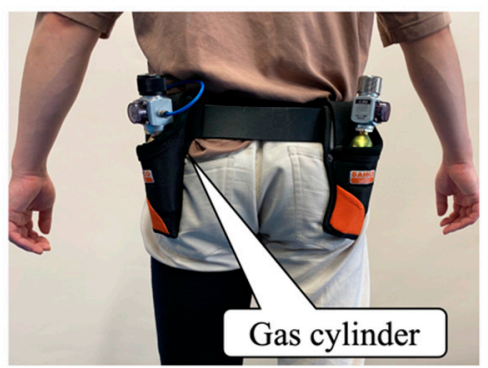

Back side

Figure 2. Setup of PAM driver system for supporting hip flexion motion. A pressure sensor is inserted under the right heel to detect the heel contact with the ground. Two McKibben-type pneumatic artificial muscles (PAMs) are attached to support hip flexion motion. An AD converter module is affixed to the shoes and a transistor switching module and gas cylinder are fixed to the waist belt.

The details of the PAM driver system have been explained in our previous reports [14,20]. Two McKibben-type PAMs with an initial length of $300 \mathrm{~mm}$ were attached to the waist and left distal end of the femur using hook and loop fasteners to support hip flexion motion. Our driver system could assist only one body part. In accordance with our previous study examined in young people $[14,20]$, we have unified the left hip joint assist. The transistor switching module $(28.0 \mathrm{~mm} \times 39.5 \mathrm{~mm} \times 13.2 \mathrm{~mm}, 18 \mathrm{~g})$ that controls the state (open or closed) of the solenoid valve was also fixed to the waist belt using hook and loop fasteners. Gas cylinders were stored in holders attached to the waist belt. The PAM contraction force was related to the length of the PAM and the magnitude of air pressure of the cylinder [13]. The air pressure was set to $200 \mathrm{kPa}$, and the force generated by the PAM contraction was approximately $30 \mathrm{~N}$ without stretching [13]. We consider the usable time of the gas cylinder to be about $7 \mathrm{~min}$. This is longer than one measurement time (about $5 \mathrm{~min}$ ). The total weight of the waist belt was approximately $1.5 \mathrm{~kg}$. A pressure sensor (FSR 400 short; Interlink Electronics, Los Angeles, CL, USA) was inserted under the right heel to detect the heel contact with the ground. An AD converter module $(28.0 \mathrm{~mm} \times 39.5 \mathrm{~mm} \times$ 
$13.2 \mathrm{~mm}, 18 \mathrm{~g}$ ) that was connected to this sensor was fixed to the shoes using hook and loop fasteners.

\subsection{Control of PAM Driver}

Figure 3 shows the control mechanism of the PAM driver system. The AD converter module samples the change in voltage caused by the change in resistance of the pressure sensor by the heel contact through a voltage divider at $100 \mathrm{~Hz}$. The criterion for the heel contact is a voltage change of $1 \mathrm{~V}$. This information is sent to a smartphone as an open sound control (OSC) message via Wi-Fi. A custom-made smartphone application is installed to control the state (open or closed) of the solenoid valves. According to the timing of the right heel contact as a trigger, the delay $\left(t_{d}\right)$ from the heel contact to the start of PAM contraction and the contraction duration of PAM $\left(t_{c}\right)$ are tuned through a slider controller with a $100 \mathrm{~ms}$ increment. Based on the smartphone message via Wi-Fi, the transistor switching module controls the state (open or closed) of the solenoid valves. When the solenoid valve is open, the PAM immediately contracts for left hip flexion through an inflow of air pressure from the gas cylinder. We observed that the network process causes a delay of about $10 \mathrm{~ms}$ in this system.

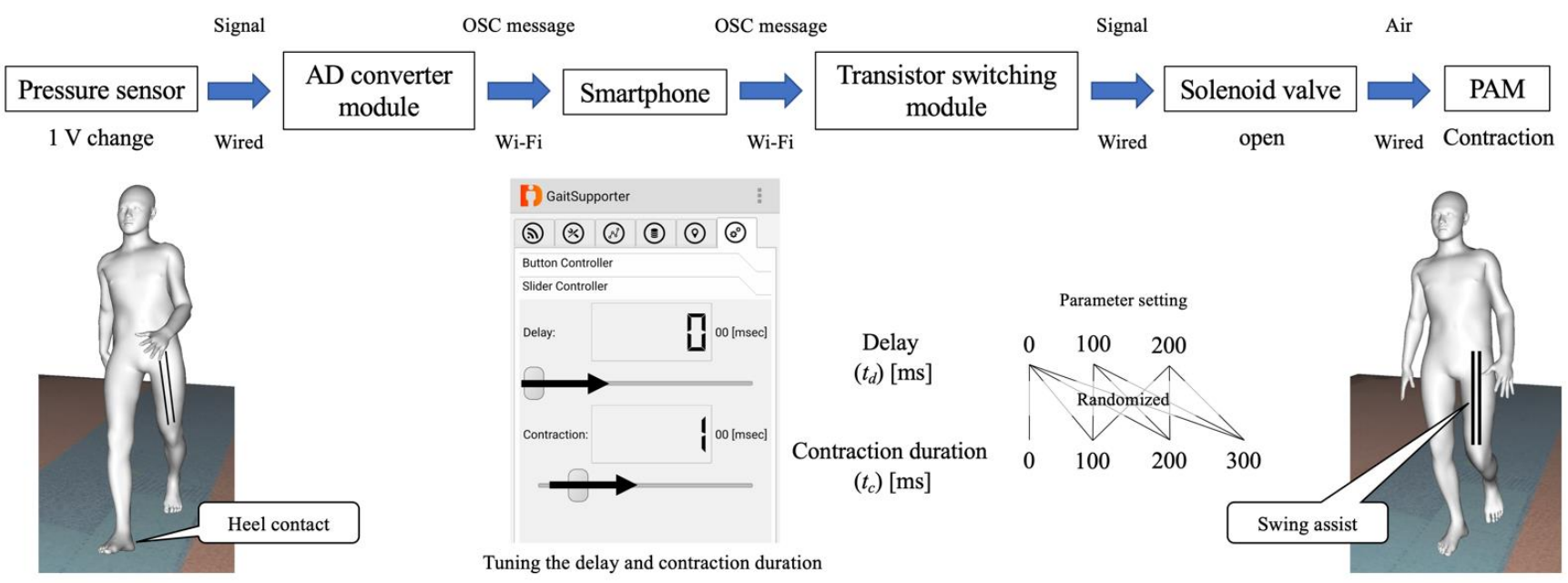

Figure 3. Control mechanism of the pneumatic artificial muscle (PAM) driver system. The signal from the pressure sensor triggers the PAM contraction. Parameter settings are randomized based on the delay from the trigger to open the solenoid valves and the contraction duration of the PAM through a slider controller with a $100 \mathrm{~ms}$ increment.

\subsection{Data Collection}

The IMU data obtained during walking trials were stored wirelessly on a personal computer using DhaibaWorks. Prior to the walking trials, a reference pose was taken to estimate the IMU orientation with the corresponding body segment [25]. Subsequently, the participants walked, approximately, $25 \mathrm{~m}$ in a straight walkway per parameter setting at a comfortable walking speed. Their hip flexion motion in the swing phase was supported by the PAM under 10 contraction parameters, including without assistance. The delay was set to 0,100 , or $200 \mathrm{~ms}$, while the contraction duration was set to 100,200 , or $300 \mathrm{~ms}$, in accordance with our previous study [20]. The order of the contraction parameters was randomized.

\subsection{Data Analysis}

Data analyses were performed offline after completing all measurements. The hip and knee joint angles were calculated using a posture-reconstruction plug-in [25] running on DhaibaWorks. This plug-in reconstructed the lower limb motion through the combination of the IMU orientation with body segments and the individual body model with a link structure [24]. The kinematic data were sampled at $60 \mathrm{~Hz}$. The validation of the hip and 
knee flexion angles and stride length relative to those measured using optical MoCap were previously evaluated using the coefficient of determination and defined as very strong $\left(R^{2} \geq 0.64\right.$ ), with confirmed values of 0.73 (hip), 0.82 (knee), and 0.86 (stride length) [26].

To ensure that the walking motion was stable, the first and last two-to-three steps were excluded from the analysis because these steps are necessary for the transition between the initiation and termination of gait and the steady-state walk of healthy people [27]. During steady-state walking, the data for 10 gait cycles were collected (Figure 4). The peak hip and knee flexion angles in the swing phase and the peak hip extension angle in the terminal stance were extracted. The hip excursion was calculated from the amplitude of the displacement between the extension and flexion angles. Moreover, the stride length was calculated as the distance of the heel feature points in the sagittal plane during the gait cycle. The sagittal plane of the body model during walking was defined as the plane that is the normal direction of the outer product of the vertical axis of the global coordinate system and the front face of the sternum. The walking speed was calculated from the stride length and time.

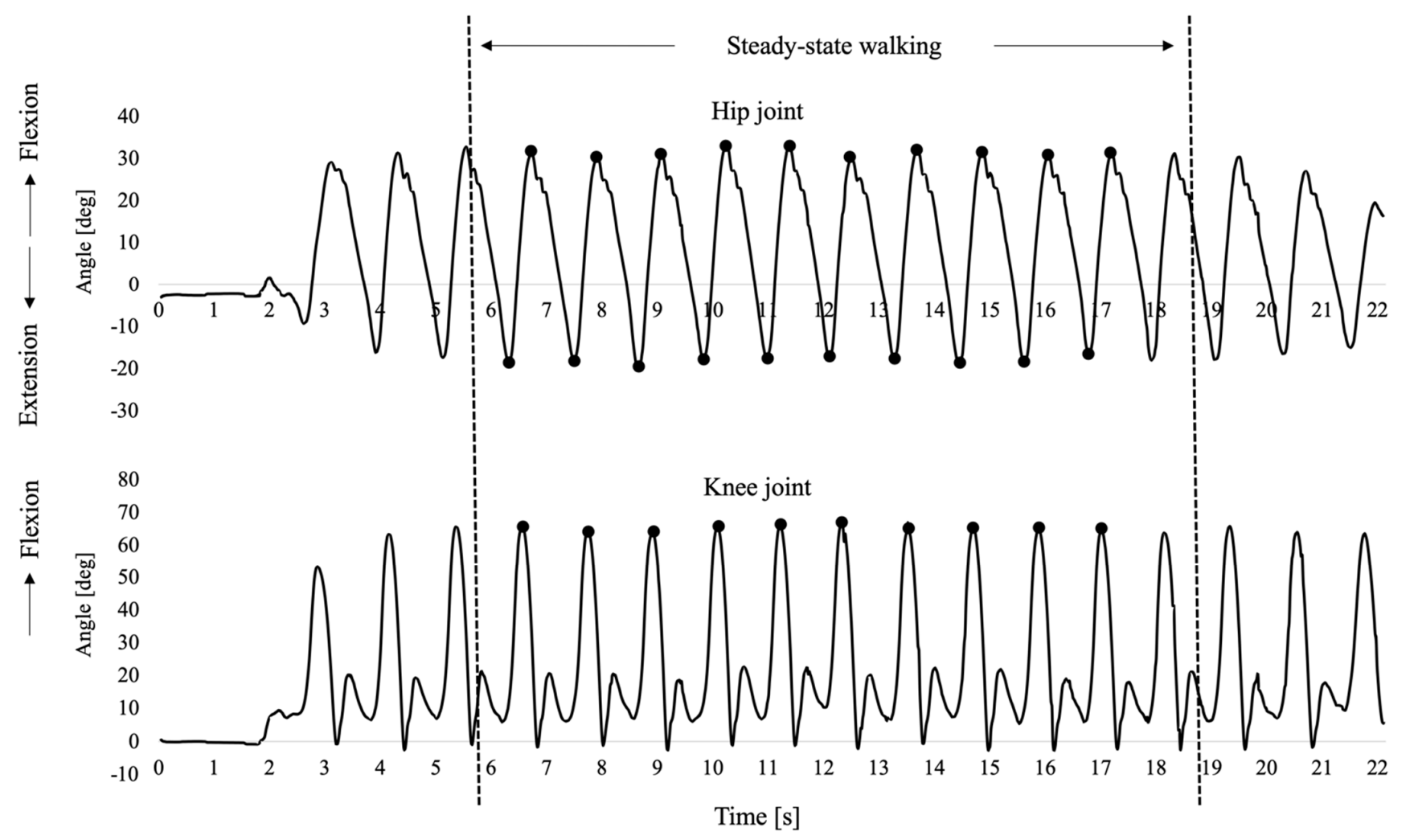

Figure 4. Example of time series data of the hip and knee flexion angles in one trial. The peak flexion angles of the hip and knee joints in the swing phase and the peak extension angle of the hip were extracted in 10 gait cycles. The hip excursion was calculated from the amplitude of the displacement between the extension and flexion angles.

We first specified the most effective parameter settings under which the hip flexion angle was maximized among all the contraction parameters. We then evaluated the relationship between walking performance and these settings. Finally, to identify the effect of the PAM assistance, the joint angles, stride length, stride time, and walking speed were compared with and without PAM assistance using a Wilcoxon signed-rank test. The statistical significance was set at $p<0.05$. All data were analyzed using SPSS version 25.0 (SPSS Inc., Chicago, IL, USA). 


\section{Results}

\subsection{Effective Parameter Settings for Each Participant}

Figure 5 shows the number of participants whose hip flexion angle was maximized under the corresponding contraction parameter settings. The combination of a $0 \mathrm{~ms}$ delay and $300 \mathrm{~ms}$ contraction was the most effective parameter setting for six participants. The combinations of a $0 \mathrm{~ms}$ delay and $200 \mathrm{~ms}$ contraction as well as a $100 \mathrm{~ms}$ delay and $300 \mathrm{~ms}$ contraction were each the effective settings for one participant. Further, the combination of a $100 \mathrm{~ms}$ delay and $200 \mathrm{~ms}$ contraction was also the most effective parameter setting for two participants. There was no trend in the relationship between the walking performance and these settings (Figure 6).

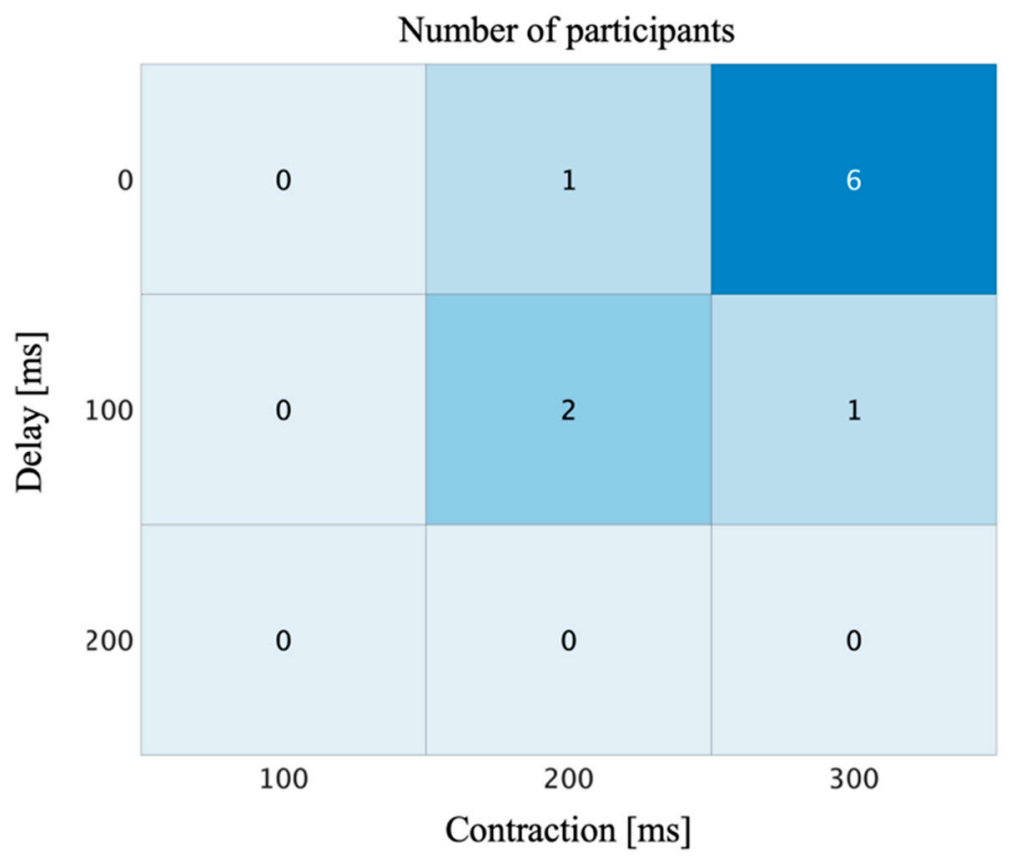

Figure 5. Heat map showing the distribution of effective parameters.

Stride length

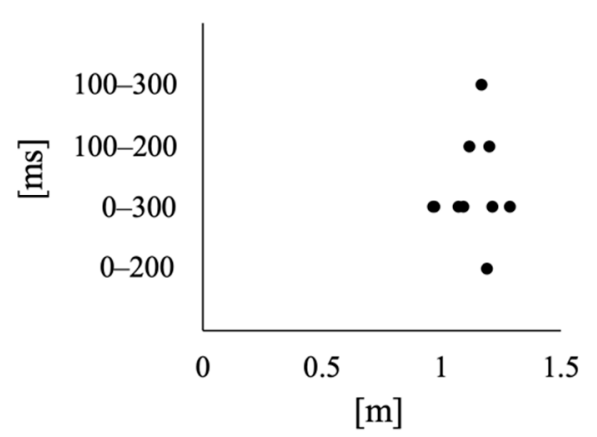

Stride time

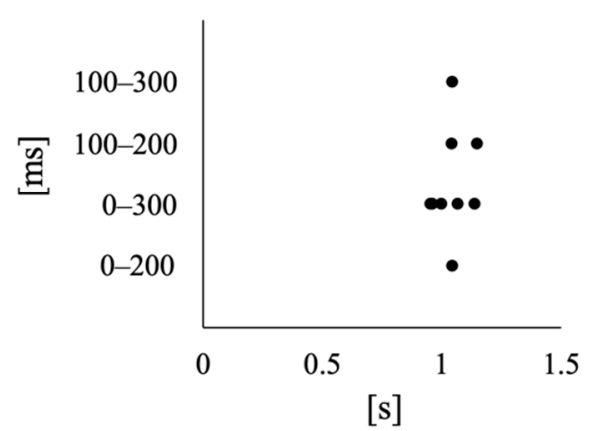

Walking speed

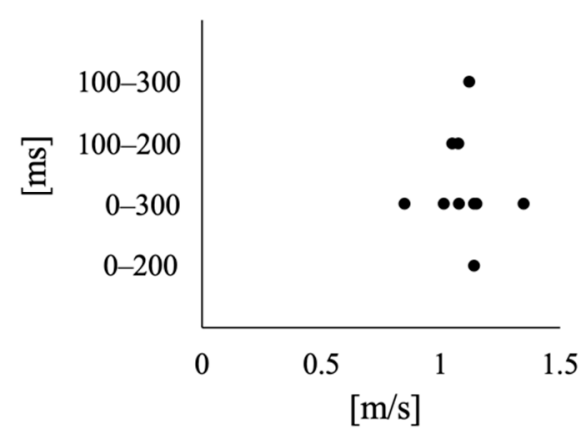

Figure 6. Scatter plots of walking performance and optimal parameter setting for each participant. The vertical axis indicates the combinations of delay-contraction duration as the effective parameter setting.

\subsection{Differences between Cases with and without PAM Assistance}

All the peak hip and knee flexion angles in the swing phase, and the hip angular excursion during a gait cycle increased significantly in the case of walking with the optimal PAM assistance (shown in Figure $7 \mathrm{a}-\mathrm{c}$ ). The magnitudes of the differences in these angles were $5.7^{\circ}(15.4 \%), 5.0^{\circ}(7.3 \%)$, and $6.1^{\circ}(13.5 \%)$, respectively. However, significant differ- 
ences were not observed in the stride length, stride time, and walking speed with the PAM assistance (shown in Figure $7 \mathrm{~d}-\mathrm{f}$ ). The magnitudes of the differences in these performances were $0.02 \mathrm{~m}(1.7 \%), 0 \mathrm{~s}(0 \%)$, and $0.02 \mathrm{~m} / \mathrm{s}(1.8 \%)$, respectively.

(a) Hip flexion angle

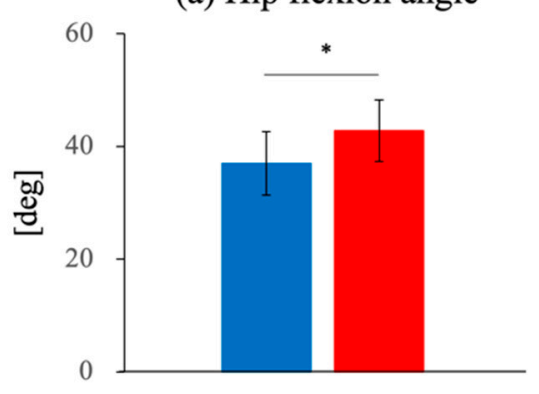

(d) Stride length

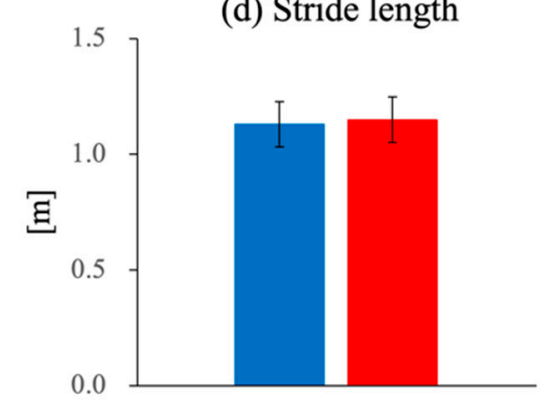

Without PAM assistance (b) Knee flexion angle

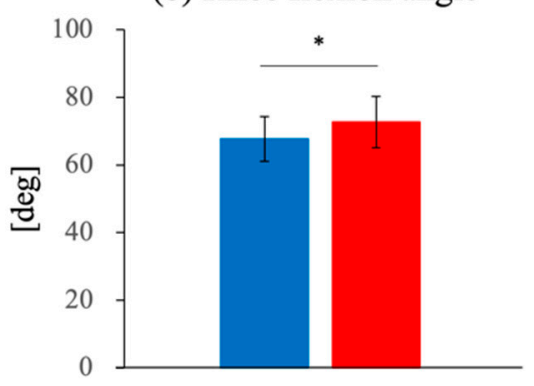

(e) Stride time

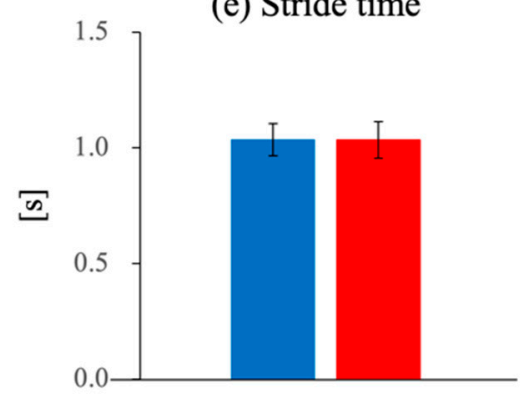

With PAM assistance (c) Hip excursion

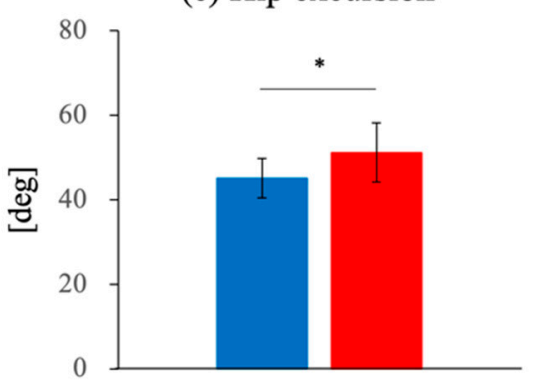

(f) Walking speed

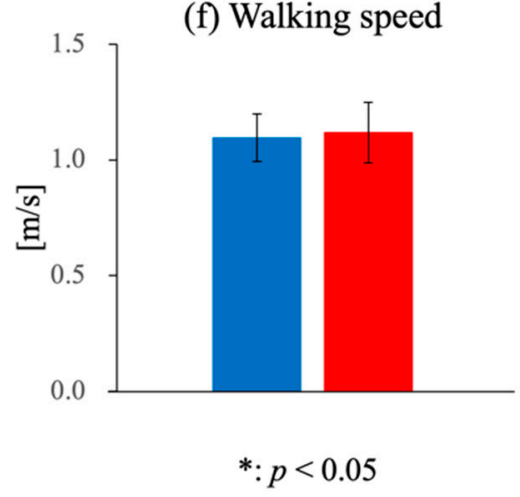

Figure 7. Differences in the hip and knee joint angles and performances between optimal pneumatic artificial muscle (PAM) assistance and lack of assistance.

\section{Discussion}

This study evaluated the effect of a PAM driver system that can control the contraction parameters of the PAM on the swing motion in the elderly. The contraction parameters needed to be optimized for each user to maximize the effectiveness of the PAM assistance. While walking with the assistance of this system, the joint angles of the hip and knee in the swing phase increased significantly without altering the gait performance. Figure 8 shows this graphically.

The parameters that realized the most effective assistance for the individuals exhibited several variations. Most of the participants had the same settings, similar to the younger participants in our previous study [14]. However, some of the older participants also had a different setting of $100 \mathrm{~ms}$ delay and $200 \mathrm{~ms}$ contraction. Previous studies have reported that the elderly exhibited longer double support time and shorter swing time in comparison with those of the younger adults [21,22]. The elderly also experienced a functional decline with aging and low balance capacity [23]. These age-related alterations may contribute to the large individual variations in the effective parameter settings. Our results indicate that the elderly had a larger variation in the parameter settings than that of the young population. For the elderly, parameter tuning was more important for effective swing assistance using PAM than for young individuals. On the other hand, there was no relationship between participants' walking performance and the parameter settings. Thus, the most effective parameter settings cannot be estimated from their ability to walk. Consequently, our driver system must be used in combination with real-time motion capture for clinical and living uses in the elderly. In the future, we will develop an online 
contraction parameter tuning system so that individual variations in effective parameters can be automatically adjusted.

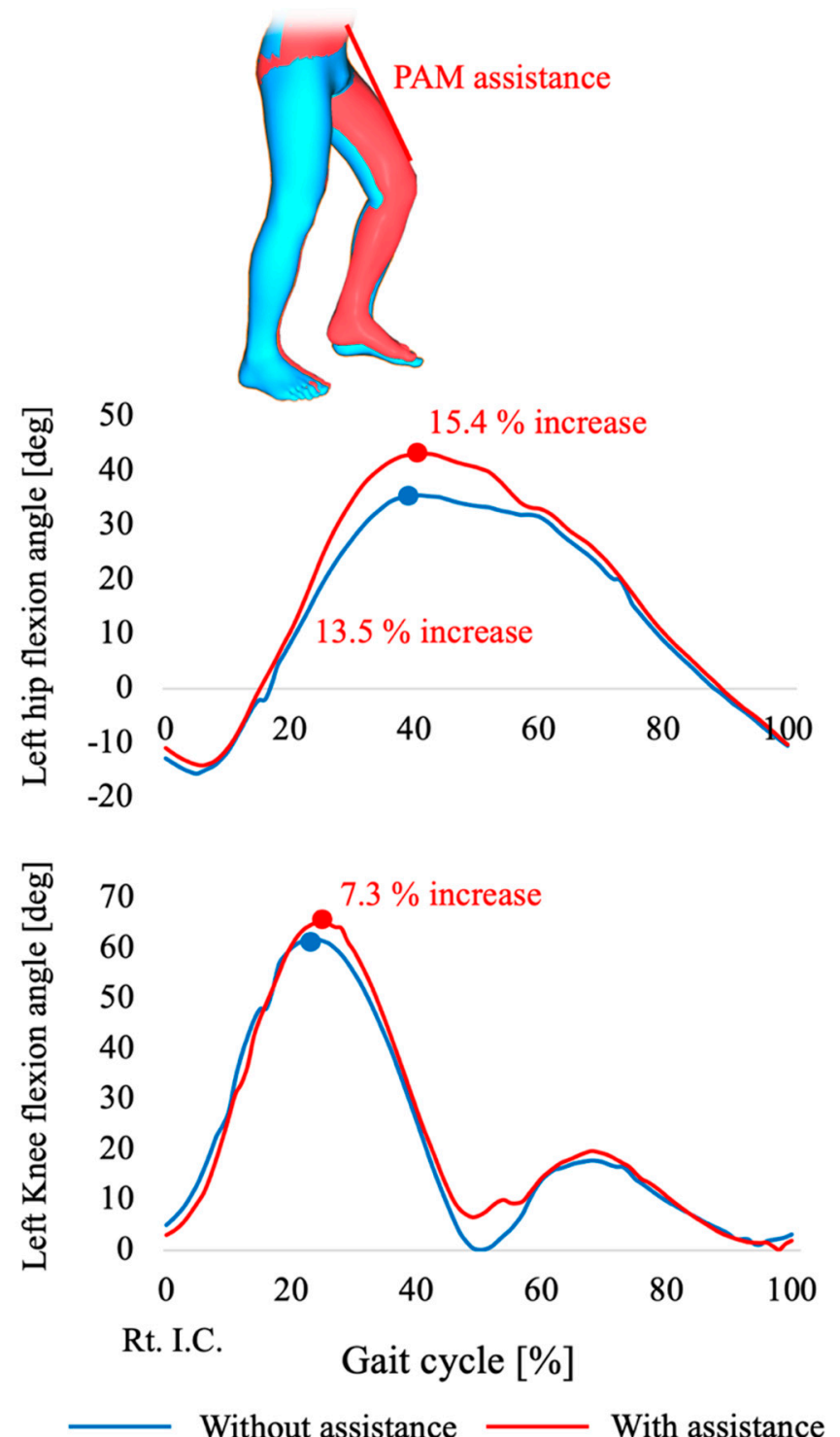

Figure 8. Graphical abstract. Example of body model and left hip and knee flexion angles in gait cycle activated by right initial contact (Rt. I.C.), which triggers the pneumatic artificial muscle (PAM) contraction. The blue and red model and lines signify without and with the PAM assistance, respectively. The peak flexion angles of hip and knee joints in the swing phase and the hip angular excursion were increased by $15.4 \%, 7.3 \%$, and $13.5 \%$, respectively, by the PAM assistance.

The peak hip and knee angles in the swing phase and the hip angular excursion were significantly increased by the PAM assistance that was set to the optimal parameters. These results are consistent with those of our previous study that focused on young individuals [14]. The height of toe clearance in the swing phase is positively correlated with the hip and knee flexion angles [6]. The increase in these angles by the PAM assistance may contribute to increasing the toe clearance. On the other hand, the increases in the hip and knee angles and the hip angular excursion of the elderly were only $15.4 \%, 7.3 \%$, and $13.5 \%$ in this study, whereas those of the young adults were $19.9 \%, 10.7 \%$, and $17.8 \%$ in our previous study [14]. This is because the elderly already had a large hip flexion angle due to forward trunk lean in comparison with that of the younger population $[28,29]$. In our studies, this angle in the elderly $\left(37.0^{\circ}\right)$ was relatively large, in comparison with that of 
the younger participants $\left(34.2^{\circ}\right)$ [14]. Owing to the low capacity of the elderly to increase the flexion angle, their amplitude of increase by the PAM assistance was smaller than that in the younger population. Nevertheless, the swing assistance with the PAM driver system enabled the increase in the hip and knee flexion angles during the swing phase in the elderly.

Meanwhile, no significant change was observed in the gait performance of the elderly. These results are not consistent with those of our previous study [14]. In general, stride length is associated with the hip joint angle [30]. Consequently, the swing assist using the PAM driver facilitated an increase in the stride length of the young participants [14]. In this study, the amplitude of alteration of the hip flexion angle in the elderly was relatively small in comparison with that in the young population. Therefore, the effect of PAM assistance on stride length may be small in the elderly. In addition, this study only provided unilateral swing assistance. Walking speed has been found to be related to physical fitness in elderly women [31]. Further studies are needed to examine assistance design, such as parameter setting and bilateral assistance, to improve the spatiotemporal parameters.

This study also has some limitations. First, since it was a cross-sectional study, we could not determine whether using a PAM driver system can decrease the risk of falls in the elderly. Second, patients with hemiplegia had more severe motor dysfunction and abnormal gait pattern than the healthy elderly. Further study is needed to examine the assistive effect by our PAM driver system and the differences in the variation of the effective parameter settings. Third, this study involved both male and female participants. By contrast, our previous study involving the young participants included only male participants, which may have caused a selection bias. Since gender differences in walking patterns [32] have been reported, gender effects should be taken into account for the analysis. Fourth, we did not measure other temporal parameters, such as the double support time and swing time of walking. To identify the temporal factors that affect the effective parameter settings, the relationship between the temporal parameters of walking and the two contraction parameters of this driver system, i.e., delay and contraction duration, needs to be examined. Fifth, it was unclear how degree assistive force was generated in our setup. Further studies are needed to perform analysis of dynamics to study the assistive force and examine assistance design, such as degree of air pressure. Sixth, it was also unclear what effect will occur if the contraction duration exceeds $400 \mathrm{~ms}$. In addition, we may need to consider changing the temporal parameters by values smaller than $100 \mathrm{~ms}$ increment. Finally, this study should be considered an exploratory study with a small sample size.

\section{Conclusions}

This study examined the effect of swing assist during walking using a PAM driver system that can control contraction parameters in the elderly. The parameter settings that realized the most effective assistance were observed in various individual variations. While walking with parameter settings for maximizing the hip flexion angle, the hip and knee flexion angles in the swing and the hip angular excursion increased significantly without altering the gait performances. Realizing effective walking assistance using wearable assistive devices and smartphones may serve as a basis for utilizing teleoperated gait rehabilitation. In the future, further studies are required to clarify whether gait rehabilitation with a PAM driver system can decrease the stumbling risk of the elderly.

Author Contributions: Conceptualization, H.T.; methodology, H.T.; software, M.T. and T.M.; validation, H.T. and T.M.; formal analysis, H.T. and T.M.; investigation, H.T. and T.M.; resources, Y.K.; data curation, H.T.; writing—original draft preparation, H.T.; writing—review and editing, T.M., M.T. and Y.K.; visualization, H.T.; supervision, M.T.; project administration, Y.K.; funding acquisition, Y.K. and M.T. All authors have read and agreed to the published version of the manuscript.

Funding: This paper is based on results obtained from a project commissioned by the New Energy and Industrial Technology Development Organization (NEDO). 
Institutional Review Board Statement: The study was conducted according to the guidelines of the Declaration of Helsinki and approved by the Institutional Review Board of the National Institute of Advanced Industrial Science and Technology (HF2019-0953).

Informed Consent Statement: Informed consent was obtained from all subjects involved in the study.

Data Availability Statement: Data sharing not applicable.

Conflicts of Interest: The authors declare no conflict of interest.

\section{References}

1. Annual Report on the Aging Society. Available online: https://www8.cao.go.jp/kourei/whitepaper/index-w.html (accessed on 12 February 2021).

2. Berg, W.P.; Alessio, H.M.; Mills, E.M.; Tong, C. Circumstances and consequences of falls in independent community-dwelling older adults. Age Ageing 1997, 26, 261-268. [CrossRef] [PubMed]

3. Begg, R.; Best, R.; Dell'Oro, L.; Taylor, S. Minimum foot clearance during walking: Strategies for the minimisation of trip-related falls. Gait Posture 2007, 25, 191-198. [CrossRef]

4. Mills, P.M.; Barrett, R.S.; Morrison, S. Toe clearance variability during walking in young and elderly men. Gait Posture 2008, 28, 101-107. [CrossRef]

5. Barrett, R.S.; Mills, P.M.; Begg, R.K. A systematic review of the effect of ageing and falls history on minimum foot clearance characteristics during level walking. Gait Posture 2010, 32, 429-435. [CrossRef] [PubMed]

6. Moosabhoy, M.A.; Gard, S.A. Methodology for determining the sensitivity of swing leg toe clearance and leg length to swing leg joint angles during gait. Gait Posture 2006, 24, 493-501. [CrossRef]

7. Murray, M.P.; Kory, R.C.; Clarkson, B.H. Walking patterns in healthy old men. J. Gerontol. 1969, 24, 169-178. [CrossRef] [PubMed]

8. Olney, S.J.; Richards, C. Hemiparetic gait following stroke. Part I: Characteristics. Gait Posture 1996, 4, 136-148. [CrossRef]

9. Bruni, M.F.; Melegari, C.; De Cola, M.C.; Bramanti, A.; Bramanti, P.; Calabrò, R.S. What does best evidence tell us about robotic gait rehabilitation in stroke patients: A systematic review and meta-analysis. J. Clin. Neurosci. 2018, 48, 11-17. [CrossRef] [PubMed]

10. Langhorne, P.; Bernhardt, J.; Kwakkel, G. Stroke rehabilitation. Lancet 2011, 377, 1693-1702. [CrossRef]

11. Wallard, L.; Dietrich, G.; Kerlirzin, Y.; Bredin, J. Effects of robotic gait rehabilitation on biomechanical parameters in the chronic hemiplegic patients. Neurophysiol. Clin. 2015, 45, 215-219. [CrossRef] [PubMed]

12. Van Kammen, K.; Boonstra, A.M.; Van Der Woude, L.H.V.; Visscher, C.; Reinders-Messelink, H.A.; Den Otter, R. Lokomat guided gait in hemiparetic stroke patients: The effects of training parameters on muscle activity and temporal symmetry. Disabil. Rehabil. 2019, 1-9. [CrossRef]

13. Thakur, C.; Ogawa, K.; Tsuji, T.; Kurita, Y. Soft wearable augmented walking suit with pneumatic gel muscles and stance phase detection system to assist gait. IEEE Robot. Autom. Lett. 2018, 3, 4257-4264. [CrossRef]

14. Toda, H.; Tada, M.; Maruyama, T.; Kurita, Y. Optimal swing support during walking using wireless pneumatic artificial muscle driver. J. Robot. Mechatron. 2021, 33, 379-385. [CrossRef]

15. Hong, J.-C.; Suzuki, S.; Fukushima, Y.; Yasuda, K.; Ohashi, H.; Iwata, H. Development of high-dorsiflexion assistive robotic technology for gait rehabilitation. In Proceedings of the 2018 IEEE International Conference on Systems, Man, and Cybernetics (SMC), Miyazaki, Japan, 7-10 October 2018; pp. 3801-3806. [CrossRef]

16. Park, Y.-L.; Chen, B.-R.; Pérez-Arancibia, N.O.; Young, D.; Stirling, L.; Wood, R.J.; Goldfield, E.C.; Nagpal, R. Design and control of a bio-inspired soft wearable robotic device for ankle-foot rehabilitation. Bioinsp. Biomim. 2014, 9, 016007. [CrossRef] [PubMed]

17. Thakur, C.; Ogawa, K.; Kurita, Y. Active passive nature of assistive wearable gait augment suit for enhanced mobility. J. Rob. Mech. 2018, 30, 717-728. [CrossRef]

18. Miyazaki, T.; Tagami, T.; Morisaki, D.; Miyazaki, R.; Kawase, T.; Kanno, T.; Kawashima, K. A motion control of soft gait assistive suit by gait phase detection using pressure information. Appl. Sci. 2019, 9, 2869. [CrossRef]

19. Tada, M. Wireless sensor and display modules for on-site motion measurement and intervention. In Proceedings of the 19th System Integration Symposium, Hiroshima, Japan, 5-8 June 2019; pp. 418-422. (In Japanese).

20. Toda, H.; Tada, M.; Maruyama, T.; Kurita, Y. Effect of contraction parameters on swing support during walking using wireless pneumatic artificial muscle driver: A preliminary study. In Proceedings of the 58th Annual Conference of the Society of Instrument and Control Engineers of Japan (SICE), Hiroshima, Japan, 10-13 September 2019; pp. 727-732. [CrossRef]

21. Begg, R.K.; Sparrow, W.A. Ageing effects on knee and ankle joint angles at key events and phases of the gait cycle. J. Med. Eng. Technol. 2006, 30, 382-389. [CrossRef]

22. Nagano, H.; Begg, R.K.; Sparrow, W.A.; Taylor, S. A comparison of treadmill and overground walking effects on step cycle asymmetry in young and older individuals. J. Appl. Biomech. 2013, 29, 188-193. [CrossRef]

23. Desai, A.; Goddman, V.; Kapadia, N.; Shay, B.L.; Szturm, T. Relationship between measures and functional performance in community-dwelling elderly people. Phys. Ther. 2010, 90, 748-760. [CrossRef]

24. Endo, Y.; Tada, M.; Mochimaru, M. Dhaiba: Development of virtual ergonomic assessment system with human models. In Proceedings of the 3rd International Digital Human Symposium, Tokyo, Japan, 20-22 May 2014. 
25. Maruyama, T.; Toda, H.; Ishii, W.; Tada, M. Inertial measurement unit to segment calibration based on physically constrained pose generation. SICE J. Control Meas. Syst. Integ. 2020, 13, 122-130. [CrossRef]

26. Maruyama, T.; Toda, H.; Kanoga, S.; Tada, M.; Endo, Y. Accuracy evaluation of human gait estimation by a sparse set of inertial measurement units. Act. Behav. Comput. 2020, 51-61. [CrossRef]

27. Mann, R.A.; Hagy, J.L.; White, V.; Liddell, D. The initiation of gait. J. Bone Jt. Surg. Am. 1979, 61, 232-239. [CrossRef]

28. Murray, M.P.; Drought, A.B.; Kory, R.C. Walking patterns of normal men. JBJS 1964, 46, 335-360. [CrossRef]

29. Kerrigan, D.C.; Todd, M.K.; Della Croce, U.; Lipsitz, L.A.; Collins, J.J. Biomechanical gait alterations independent of speed in the healthy elderly: Evidence for specific limiting impairments. Arch. Phys. Med. Rehabil. 1998, 79, 317-322. [CrossRef]

30. Smidt, G.L. Hip motion and related factors in walking. Phys. Ther. 1971, 51, 9-22. [CrossRef] [PubMed]

31. Ciprandi, D.; Zago, M.; Bertozzi, F.; Sforza, C.; Galvani, C. Influence of energy cost and physical fitness on the preferred walking speed and gait variability in elderly women. J. Electromyogr. Kinesiol. 2018, 43, 1-6. [CrossRef]

32. Kerrigan, D.C.; Todd, M.K.; Croce, U.D. Gender differences in joint biomechanics during walking; Normative study in young adults. Am. J. Phys. Med. Rehabil. 1998, 77, 2-7. [CrossRef] [PubMed] 